\title{
SPATIOTEMPORAL ANALYSIS OF AMBIENT AIR POLLUTION EXPOSURE AND RESPIRATORY INFECTIONS CASES IN BEIJING
}

\author{
An Zhang, Fang Zhou, Lili Jiang, Qingwen Qi, Jinfeng Wang \\ State Key Laboratory of Resources and Environmental Information System, Institute of Geographical Sciences and Natural Resources \\ Research, Chinese Academy of Sciences, Beijing, China
}

\begin{abstract}
SUMMARY
Background: Ambient air pollutants $\left(\mathrm{PM}_{2.5}\right)$ are components of persistent haze in Beijing during the autumn and winter seasons.

Materials: We collected hourly $\mathrm{PM}_{2.5}$ monitoring data for 35 days from 35 sites in Beijing during 2012. We also identified patients developing respiratory infections during the same time period in the same locale. A BME model was used to simulate environmental exposure concentrations over the course of each day. A medical accessibility analysis was performed to exclude the impact of medical availability on the analysis. A spatial analysis was included in the evaluation of the relationship between exposure duration and concentration of $\mathrm{PM}_{2.5}$ with the development of acute respiratory disease.

Results: A low concentration of $\mathrm{PM}_{2.5}$ (greater than $35 \mu \mathrm{g} / \mathrm{m}^{3}$ and less than $115 \mu \mathrm{g} / \mathrm{m}^{3}$ ) for at least 3 days was associated with an increased risk of acute respiratory disease. A high concentration of $\mathrm{PM}_{2.5}$ (greater than $115 \mu \mathrm{g} / \mathrm{m}^{3}$ ) was associated with an increased risk of infection even after 1 day of exposure.
\end{abstract}

Key words: $\mathrm{PM}_{2,5}$, respiratory infection cases, exposure duration and concentration, cumulative effect, spatiotemporal analysis

Address for correspondence: Lili Jiang, State Key Laboratory of Resources and Environmental Information System, Institute of Geographical Sciences and Natural Resources Research, Chinese Academy of Sciences, Room 1335, A11, Datun Road, 100101 Beijing, China. E-mail: jiangll@ igsnrr.ac.cn

\section{INTRODUCTION}

Ambient air pollutants $\left(\mathrm{PM}_{25}\right)$ are main components of persistent haze in Beijing during the autumn and winter seasons (1). Overexposure to $\mathrm{PM}_{2.5}$ poses a risk to public health. Fine particles are more strongly associated than coarse particles with acute respiratory health risks $(2,3)$. Zhang et al. has reported the population exposure to these particles in high-exposure areas of Beijing (4) during the autumn of 2012. Air pollution has been shown to contribute to patient morbidity and mortality (5-8). The risk associated with different duration of exposure and amount of exposure has not been well defined.

Epidemiological evidence suggests that air pollution is a contributing cause of respiratory and cardiovascular disease morbidity and mortality (9-11). The character of the relationship between exposure duration and concentration of particulate matter with population mortality has been one of the critical and difficult problems in air pollution epidemiologic studies (12). Previous evaluations have usually been based on case studies $(13,14)$. These studies do not include environmental exposure data, and instead present city average environmental concentrations to estimate the exposure of each clinical case. Environmental exposure concentration differences during the day and night have not been considered. Du X. et al. (15) evaluated the exposure of adults and children to fine particles using a personal $\mathrm{PM}_{2.5}$ exposure monitor. There was a strong association between fixed-site concentration and personal exposure concentration, suggesting that ambient concentrations have a large role in personal exposure to fine particles.
We collected hourly $\mathrm{PM}_{2.5}$ concentration data from 35 sites in Beijing and acute respiratory infection case data from October 8th, 2012 to November 11th, 2012. A spatiotemporal simulation model was used to simulate environmental exposure concentrations during the day and night. A spatial and statistical case studies were undertaken to better understand the relationship between exposure duration and concentration of particulate matter with acute respiratory disease.

\section{MATERIALS AND METHODS}

$\mathbf{P M}_{2.5}$ Data

The Beijing Environmental Protection Bureau (BJEPB) established 35 air quality monitoring stations in Beijing in October 2012 through the Centre of the City Environmental Protection Monitoring Website Platform (http://zx.bjmemc.com.cn/). On this website the $\mathrm{PM}_{2.5}$ concentration data measured in $\mu \mathrm{g} / \mathrm{m}^{3}$ (microgram per cubic meter) are updated on the hour. The location of monitoring stations for fine particles in the air 2.5 micrometers or less in size $\left(\mathrm{PM}_{2.5}\right)$ has been previously reported (4). We collected $\mathrm{PM}_{2.5}$ concentration data for 35 consecutive days (840 hours) from October 8th, 2012 to November 11th, 2012 from these sites.

\section{Respiratory Infection Cases Data}

The frequency of acute respiratory infections in this area was recorded during the same time period. One thousand and 
fifty-seven cases were identified, of which, 917 were considered valid cases with supporting data. Data was entered into an acute respiratory infection data form (Table 1). The form included the date of diagnosis (Date/Clinic), duration of the illness in days (Duration), date of the respiratory illness onset (Date/Ill), place of residence (Add/Residence), and commuting locale (Add/Work). Commuting locales included work address and school address. Individual's exposure duration and concentration at the place of residence and commuting locale was estimated. Addresses are shown as $* * *$ here to maintain patient privacy.

\section{Spatiotemporal Simulation of $\mathbf{P} \mathbf{M}_{2.5}$ Concentrations}

$\mathrm{PM}_{2.5}$ concentrations in each sampling area were simulated using the sample data. The BME (Bayesian Maximum Entropy) technique was used for this simulation based on previous spatiotemporal air pollution modeling studies $(16,17)$. Graphical user interface (SEKS-GUI) (18) software was used to perform the spatiotemporal simulation. The confidence coefficient of the space-time prediction was maintained at a high level. We shrink the simulation size in time and spatial dimension, and at the same time, encrypt it in spatial dimension. Time predictions were performed every hour, consistent with the monitoring frequency. To improve the fit of the covariance model, each day was fit separately. Each day's simulation was performed by expanding the monitoring data to include the 5 hours before and 5 hours after each time point analyzed. Using this approach, 34 hours of sample data were used to simulate the spatiotemporal distribution of 24 hours of $\mathrm{PM}_{2.5}$ concentrations. $1 \mathrm{~km}$ was set as the spatial interval of simulated points in the $\mathrm{x}$ and $\mathrm{y}$ directions. The actual time and space simulation included 2,438 data points (Fig. 1). The simulation covered the entire urban area of Beijing.

SEKS-GUI software was used to model the time and space variations of $\mathrm{PM}_{25}$. Graphical similarity matching between sample covariance and simulation covariance was used for both time and space model types.

\section{Analysis of Accessibility to Hospital Care}

Medical care provided in private medical institutions including family doctors in China is usually very expensive. In Beijing, patients usually go to the hospital instead of looking for a family doctor. Time spent on the way to a hospital clinic seemed to affect medical access. We assume that patients who suffered the acute respiratory disease usually went to the nearest hospital. A medical accessibility model was constructed based on the time spent to reach the clinic. First, the road network in the study area was divided into a number of grids. The grid size was arbitrarily defined as $100 \mathrm{~m} \times 100 \mathrm{~m}$. The area of every grid was $0.01 \mathrm{~km}^{2}$. Each grid area was treated as a homogeneous area of accessibility. A speed value was assigned to each road in the network. Different road types were categorized as urban express ways, city thoroughfares and minor arterial roads. A velocity assumption was used for each road category (Table 2). ArcGIS software was used to select the closest hospital based on the speed and load of the road network.

\section{Table 2. Speed by road category $(\mathrm{km} / \mathrm{h})$}

\begin{tabular}{|c|c|c|}
\hline Expressways & City thoroughfares & Minor arterial roads \\
\hline 60 & 40 & 20 \\
\hline
\end{tabular}

Table 1. Collection form used to record respiratory infection cases data

\begin{tabular}{|c|c|c|c|c|c|}
\hline ID & Date/Clinic & Add/Work & Add/Residence & Duration & Date/lll \\
\hline 21 & $10-12$ & ${ }^{* * *}$ & ${ }^{* * *}$ & 4 & $2012-10-8$ \\
\hline 22 & $10-12$ & ${ }^{* * *}$ & ${ }^{* * *}$ & 3 & $2012-10-9$ \\
\hline 23 & $10-12$ & ${ }^{* * *}$ & ${ }^{* * *}$ & 3 & $2012-10-9$ \\
\hline 24 & $10-13$ & $* * *$ & $* * *$ & 1 & $2012-10-12$ \\
\hline$\ldots \ldots$ & $\ldots \ldots$ & $\ldots \ldots$ & $\ldots \ldots$ & $\ldots \ldots$ \\
\hline
\end{tabular}

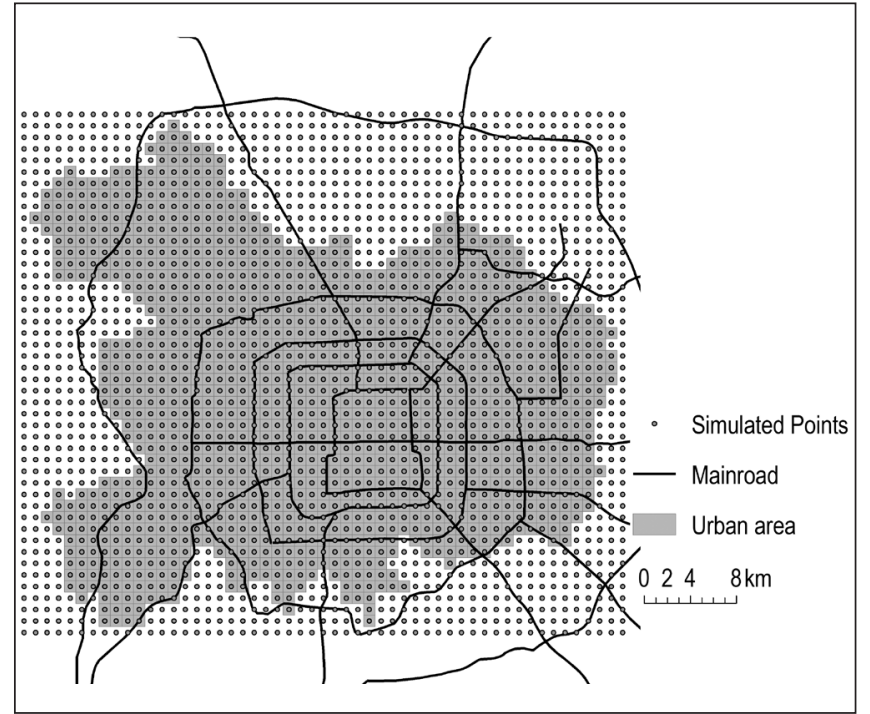

Fig. 1. Distribution of simulated points at any time $t_{i}$

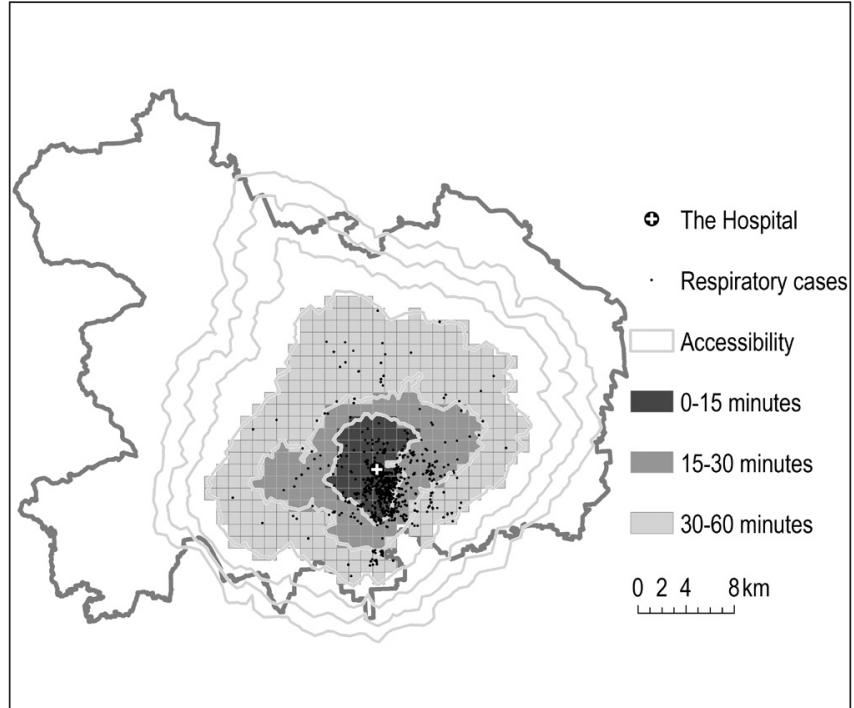

Fig. 2. Distribution of cases by accessibility zone. 
When calculating the shortest path, we divided our study area into several square grids. The cost of time from every node (central point of each grid) to its adjacent 8 grids was put in a queue, arrayed in descending order. The minimum value was selected to get the time cost from any node to every other node in the study area. Accessibility time from home to hospital was calculated. Affected patients usually went to the nearest hospital, so the facility, number of beds and available equipment did not alter access.

Spatial Statistics for Exposure-response Relationship 822 of the 917 valid cases had a time spent less than 1 hour to the local hospital in the accessibility analysis. We divided the 1 hour accessibility zone into 3 groups: 0-15 minutes, 15-30 minutes, and 30-60 minutes. There are 523, 193, 106 cases in each accessibility zone, respectively. Figure 2 presents the distribution of these 3 zones, and the cases location in their respective zones. The statistical analysis of the relationship between $\mathrm{PM}_{2.5}$ exposure and infection was conducted based on this accessibility partition.

The small number of respiratory infections did not allow demonstration of a correlation between the number of cases in each $1 \mathrm{~km}^{2}$ grid and its corresponding $\mathrm{PM}_{2.5}$ concentration or a correlation between the daily number of cases and the daily average $\mathrm{PM}_{2.5}$ concentration.

An analysis was then performed based on individual location during the day. Each patient's exposure grid at night was considered to be that of the $1 \mathrm{~km}^{2}$ grid containing the residential address. The day of the week of the illness onset was then taken into consideration. If it was a weekday, then each patient's exposure grid in the daytime was the $1 \mathrm{~km}^{2}$ grid containing the commuting address. If it was a weekend, the daytime exposure grid was the $1 \mathrm{~km}^{2}$ grid containing the residential address. Exposure time was calculated from 8:00 a.m. to 8:00 p.m. The average $\mathrm{PM}_{2.5}$ concentration of nighttime and daytime exposure on the day getting sick, the day before getting sick and two days before getting sick was then determined. Three average concentration exposure thresholds, 35 $\mu \mathrm{g} / \mathrm{m}^{3}, 75 \mu \mathrm{g} / \mathrm{m}^{3}$ and $115 \mu \mathrm{g} / \mathrm{m}^{3}$ (according to the China Ambient
Air Quality Standards (GB 3095-2012) (19) were used to calculate exposure (Tables 3-5). We did not get enough time for series cases data. A long lag time such 1 week (7 days) time series analysis is not supported. Thus, the number of cases occurring in 1 day (24 hours), 2 days (48 hours) or 3 days ( 72 hours) was counted.

\section{RESULTS}

Table 3 shows the results of the $0-15$ minute accessibility zone. Two hundred eighty-eight individuals were exposed to relatively low concentrations of $\mathrm{PM}_{2.5}$ (average concentration 35 to $75 \mu \mathrm{g}$ / $\left.\mathrm{m}^{3}\right) 24$ hours before the onset of respiratory symptoms. Three hundred and forty patients were exposed to the same level of $\mathrm{PM}_{2.5}$ 48 hours before disease onset. Four hundred and fifteen patients were exposed to the same level of $\mathrm{PM}_{2.5} 72$ hours before disease onset. Two consecutive days of low exposure were associated with more respiratory infections than one day, and three consecutive days of the same level of exposure were associated with more infections than two days. Longer exposure to low concentrations of $\mathrm{PM}_{2.5}$ was associated with a higher risk of infection.

Concentrations of 75 to $115 \mu \mathrm{g} / \mathrm{m}^{3}$ followed a similar trend. Higher concentrations were associated with the reverse trend. Longer exposure of the highest concentration of $\mathrm{PM}_{2.5}$ was associated with a lower risk of infection.

Patients in higher accessibility zones had a similar risk of infection for each concentration group (Tables 4 and 5).

\section{DISCUSSION}

People close to the hospital (0-15 minute accessibility zone) had relatively easy access to medical care. These data show correlation between acute respiratory disease and $\mathrm{PM}_{2.5}$ exposure. $\mathrm{Pa}-$ tients with easy access ( $0-15$ minute accessibility zone) exposed to a low or medium concentration of $\mathrm{PM}_{2.5}$ had a direct correlation between the number of days of exposure and the number of acute

Table 3. Number of cases versus $P M_{2.5}$ exposure in the $0-15$ minute accessibility zone

\begin{tabular}{|l|c|c|c|}
\hline Number of cases $(0-15$ minutes $)$ & In 24 hours & In 48 hours & In 72 hours \\
\hline $75 \mu \mathrm{g} / \mathrm{m}^{3}>$ Average concentration $\geq 35 \mu \mathrm{g} / \mathrm{m}^{3}$ & 288 & 340 & 415 \\
\hline $115 \mu \mathrm{g} / \mathrm{m}^{3}>$ Average concentration $\geq 75 \mu \mathrm{g} / \mathrm{m}^{3}$ & 170 & 212 & 249 \\
\hline Average concentration $\geq 115 \mu \mathrm{g} / \mathrm{m}^{3}$ & 123 & 120 & 56 \\
\hline
\end{tabular}

Table 4. Number of cases versus $P M_{2.5}$ exposure in the 15-30 minute accessibility zone

\begin{tabular}{|l|c|c|c|}
\hline Number of cases (15-30 minutes) & In 24 hours & In 48 hours & In 72 hours \\
\hline $75 \mu \mathrm{g} / \mathrm{m}^{3}>$ Average concentration $\geq 35 \mu \mathrm{g} / \mathrm{m}^{3}$ & 91 & 130 & 130 \\
\hline $115 \mu \mathrm{g} / \mathrm{m}^{3}>$ Average concentration $\geq 75 \mu \mathrm{g} / \mathrm{m}^{3}$ & 58 & 70 & 69 \\
\hline Average concentration $\geq 115 \mu \mathrm{g} / \mathrm{m}^{3}$ & 43 & 32 & 32 \\
\hline
\end{tabular}

Table 5. Number of cases versus $P M_{2.5}$ exposure in the 30-60 minute accessibility zone

\begin{tabular}{|l|c|c|c|}
\hline Number of cases (30-60 minutes) & In 24 hours & In 48 hours & In 72 hours \\
\hline $75 \mu \mathrm{g} / \mathrm{m}^{3}>$ Average concentration $\geq 35 \mu \mathrm{g} / \mathrm{m}^{3}$ & 61 & 75 & 84 \\
\hline $115 \mu \mathrm{g} / \mathrm{m}^{3}>$ Average concentration $\geq 75 \mu \mathrm{g} / \mathrm{m}^{3}$ & 43 & 48 & 50 \\
\hline Average concentration $\geq 115 \mu \mathrm{g} / \mathrm{m}^{3}$ & 36 & 30 & 22 \\
\hline
\end{tabular}


respiratory infections. Patients exposed to high concentrations of $\mathrm{PM}_{2.5}$ had similar rates of infection for all durations of exposure. Patients in the 15-30 and 30-60 minute accessibility zones had a similar frequency of infection.

People spend most of the time indoors. In Beijing, residents often open windows to ventilate during autumn, especially in November - the time before the heating season. Thus the difference between indoor and outdoor particulate matter concentrations is not so big. Smoking habit is widespread in China. If somebody smokes indoors, $\mathrm{PM}_{25}$ concentration is much higher indoors then outdoors. We did not investigate whether the respiratory infection cases occurred in a smoking environment. Smoking can lead to respiratory diseases. But there is the exposure-response relationship between $\mathrm{PM}_{2.5}$ exposure and infection. Exposure to concentrations of $\mathrm{PM}_{2.5}$ greater than $35 \mu \mathrm{g} / \mathrm{m}^{3}$ and less than $115 \mu \mathrm{g} / \mathrm{m}^{3}$ for at least three days were a risk factors for acute respiratory disease. Exposure to concentrations of $\mathrm{PM}_{25}$ greater than $115 \mu \mathrm{g} / \mathrm{m}^{3}$ was a risk factor for infection even after one day of exposure. Exposure to even low concentrations of $\mathrm{PM}_{2.5}$ was not safe over time. Cities with air pollution will need to allocate more medical resources for respiratory care during peak periods of air contaminants.

\section{CONCLUSIONS}

We collected hourly $\mathrm{PM}_{2.5}$ monitoring data for 35 consecutive days from 35 sites in Beijing in 2012. We also identified patients with respiratory infections during the same time period and locale. We used a BME model to simulate environmental exposure to different concentrations of $\mathrm{PM}_{2.5}$ by time of a day. A medical accessibility analysis was performed to evaluate the impact of medical availability on the risk of infection analysis. The small number of respiratory infections did not permit demonstration of a correlation between the number of cases and the $\mathrm{PM}_{2.5}$ concentration. Thus, we used a simple spatial statistics for exposure-response relationship.

With the limited respiratory infections cases, the following conclusions were reached:

When the concentration of $\mathrm{PM}_{2.5}$ was relatively low (greater than $35 \mu \mathrm{g} / \mathrm{m}^{3}$ and less than $115 \mu \mathrm{g} / \mathrm{m}^{3}$ ) for several days, at least three days of exposure were needed to cause acute respiratory disease.

When the concentration of $\mathrm{PM}_{2.5}$ was relatively high (greater than $115 \mu \mathrm{g} / \mathrm{m}^{3}$ ), only one day of exposure was needed to cause infection.

These significant findings help define the relationship between $\mathrm{PM}_{2.5}$ exposure duration and concentration of $\mathrm{PM}_{2.5}$ with the development of acute respiratory disease.

\section{Acknowledgements}

This study is supported by the National Natural Science Foundation of China (41201412), National Natural Science Foundation of China (41101447), National Natural Science Foundation of China (41471414), and Basic Science-technological Special Working: Compilation of the National Atlases of the People's Republic of China (New Century Version) (No. 2013FY112800).

\section{Authors' Contributions}

LLJ and AZ conceived the paper and drafted the manuscript. AZ and FZ performed the analysis and wrote the paper. $\mathrm{FZ}$ and $\mathrm{AZ}$ helped to analyze the original data. QWQ and JFW advised on methods. All authors read and approved the final manuscript.

\section{Conflicts of Interest}

None declared

\section{REFERENCES}

1. Yuan Y, Liu D, Che R, Dong X. Research on the pollution situation of atmospheric particulates during Autumn in Beijing city. Ecol Environ. 2007;(1):18-25.

2. Schwartz J, Neas LM. Fine particles are more strongly associated than coarse particles with acute respiratory health effects in schoolchildren. Epidemiology. 2000 Jan;11(1):6-10.

3. Greene NA, Morris VR. Assessment of public health risks associated with atmospheric exposure to PM2.5 in Washington, DC, USA. Int J Environ Res Public Health. 2006 Mar;3(1):86-97.

4. Zhang A, Qi Q, Jiang L, Zhou F, Wang J. Population exposure to PM2.5 in the urban area of Beijing. PLoS One. 2013 May 2;8(5):e63486. doi: 10.1371/journal.pone.0063486.

5. Haley VB, Talbot TO, Felton HD. Surveillance of the short-term impact of fine particle air pollution on cardiovascular disease hospitalizations in New York State. Environ Health. 2009 Sep 22;8:42.

6. Dockery DW, Pope CA 3rd, Xu X, Spengler JD, Ware JH, Fay ME, et al. An association between air pollution and mortality in six U.S. cities. N Engl J Med. 1993 Dec 9;329(24):1753-9.

7. Katsouyanni K, Touloumi G, Spix C, Schwartz J, Balducci F, Medina S, et al. Short-term effects of ambient sulphur dioxide and particulate matter on mortality in 12 European cities: results from time series data from the APHEA project. Air Pollution and Health: a European Approach. BMJ. 1997 Jun 7;314(7095):1658-63.

8. Pope CA 3rd, Thun MJ, Namboodiri MM, Dockery DW, Evans JS, Speizer FE, et al. Particulate air pollution as a predictor of mortality in a prospective study of U.S. adults. Am J Respir Crit Care Med. 1995 Mar;151(3 Pt 1):669-74.

9. Künzli N, Kaiser R, Medina S, Studnicka M, Chanel O, Filliger P, et al. Public-health impact of outdoor and traffic-related air pollution: a European assessment. Lancet. 2000 Sep 2;356(9232):795-801.

10. Obot CJ, Morandi MT, Beebe TP Jr, Hamilton RF, Holian A. Surface components of airborne particulate matter induce macrophage apoptosis through scavenger receptors. Toxicol Appl Pharmacol. 2002 Oct 15;184(2):98-106.

11. Baulig A, Sourdeval M, Meyer M, Marano F, Baeza-Squiban A. Biological effects of atmospheric particles on human bronchial epithelial cells. Comparison with diesel exhaust particles. Toxicol In Vitro. 2003 Oct-Dec;17(5-6):567-73.

12. Zhang YS, Yang MJ, Pan XC. Character of exposure-response relationship between particulate matter and population mortality. J Environ Health. 2007;(10):830-3.

13. Li P, Xin J, Wang Y, Wang S, Pan X, Li G. Research on the impact of Beijing atmospheric particulate pollution on population death rate. Climatic and Environmental Changes and Human Health. 2012;S(7):1-10. (In Chinese.)

14. Fann N, Lamson AD, Anenberg SC, Wesson K, Risley D, Hubbell BJ. Estimating the national public health burden associated with exposure to ambient PM2.5 and ozone. Risk Anal. 2012 Jan;32(1):81-95.

15. Du X, Kong Q, Ge W, Zhang S, Fu L. Characterization of personal exposure concentration of fine particles for adults and children exposed to high ambient concentrations in Beijing, China. J Environ Sci (China). 2010;22(11):1757-64.

16. Pang W, Christakos G, Wang JF. Comparative spatiotemporal analysis of fine particulate matter pollution. Environmetrics. 2010;21(3-4):305-17.

17. Yu HL, Wang CH, Liu MC, Kuo YM. Estimation of fine particulate matter in Taipei using landuse regression and bayesian maximum entropy methods. Int J Environ Res Public Health. 2011 Jun;8(6):2153-69.

18. Yu HL, Kolovos A, Christakos G, Chen JC, Warmerdam S, Dev B. Interactive spatiotemporal modelling of health systems: the SEKS-GUI framework. Stoch Environ Res Risk Assess. 2007;21(5)555-72.

19. People's Republic of China, Ministry of Environmental Protection. Ambient air quality standards, GB 3095-2012. Beijing: China Environmental Science Press; 2012. 